\title{
Characteristics of Pi 2 magnetic pulsations observed at the CPMN stations: A review of the STEP results
}

\author{
Kiyohumi Yumoto and the CPMN Group \\ Department of Earth and Planetary Sciences, Kyushu University 33, Fukuoka 812-8581, Japan
}

(Received July 14, 1999; Revised June 13, 2001; Accepted August 9, 2001)

\begin{abstract}
From analyses of magnetic data from the Circum-pan Pacific Magnetometer Network (CPMN) stations, we can find the following wave characteristics of Pi 2 magnetic pulsations. (1) Pi 2 pulsations observed on the ground are an ensemble of various hydromagnetic modes excited at high, middle, low, and equatorial latitudes. Each mode exhibits its own propagation (timing) and spatial illumination. (2) There are apparent longitudinal propagation and latitudinal time delays of the maximum Pi 2 magnetic energy among the CPMN stations within 100 sec. (3) When a single low-latitude station is located in the sectors of 00-24 hr LT, 20-03 hr local time (LT), and 23-01 hr LT, respectively, $62 \%, 79 \%$, and $100 \%$ of auroral breakups identified by the Polar satellite have associated Pi 2 s. $66 \%$ of the low-latitude Pi 2 s occur within 1 min of the auroral breakups, and $85 \%$ within 2 min. Pi 2 s are still a good indicator of substorm onsets, but they should be used with care.
\end{abstract}

\section{Introduction}

At the onset of magnetospheric substorms, impulsive hydromagnetic oscillations with periods of 40-150 sec, so called Pi 2 magnetic pulsations, occur globally in the magnetosphere. Pi 2 magnetic pulsations recorded on the induction magnetogram at low latitudes appear at the beginning part of positive H-componet bays in the ordinary magnetogram at low latitudes (see figure 39 of Saito, 1969), and its onsets show one-to-one correspondence to individual bays (see figure 42 of Saito, 1969). Low-latitude Pi 2 magnetic pulsations have been regarded as a good indicator of substorm onsets for the past two decades (e.g., Saito et al., 1976; Sakurai and Saito, 1976; Yeoman et al., 1994). But recently, Liou et al. (2000) compared Pi 2 onsets observed at a single station (Kakioka, $L=1.07$ ) with the auroral breakups identified by the Polar ultraviolet images. The identifying substorm onset with the Pi 2 alone is often ambiguous, and a Pi 2 onset observed at Kakioka is sometimes delayed by as long as $2 \mathrm{~min}$ from an auroral breakup identified by the Polar satellite. They suggested that Pi 2 observed at a single low-latitude station may not be as a good indicator of the substorm onset as it was thought to be.

The source of nighttime Pi 2 pulsations is believed to be a sudden change in magnetospheric configuration or convection during the substorm expansion phase. This change may be caused by earthward plasma flows from the reconnection region and/or a sudden generation of fieldaligned currents (FACs) between the polar ionosphere and the magnetospheric plasmasheet in association with the disruption of cross-tail currents (see references in Yumoto, 1986, 1988). The formation of the substorm current wedge (SCW; McPherron et al., 1973) also causes the magnetic bay

Copy right (c) The Society of Geomagnetism and Earth, Planetary and Space Sciences (SGEPSS); The Seismological Society of Japan; The Volcanological Society of Japan; The Geodetic Society of Japan; The Japanese Society for Planetary Sciences. variations at mid- and low-latitudes. Ohtani et al. (1999) asserted that the tail current disruption is a unique process rather than a direct consequence of the near-Earth neutral line formation, and took over the near-Earth reconnection process as a major role in the substorm dynamics.

After the Circum-pan Pacific Magnetometer Network (CPMN) have been constructed along the $210^{\circ}$ magnetic meridian (MM) (Yumoto and the $210^{\circ} \mathrm{MM}$ Magnetic Observation Group, 1996) and the magnetic equator (Tachihara et al., 1996) as shown in Fig. 1, it is now possible to investigate global characteristics of Pi 2 pulsations and one-to-one correspondence between Pi $2 \mathrm{~s}$ and substorm onsets (i.e. auroral breakups), and then examine if nighttime Pi 2 pulsations are just an excited oscillation/wave, and/or have a role of trigger/guide for magnetospheric substorms. In order to reexamine whether Pi 2 pulsations are still a good indicator of magnetospheric substorm onsets or not, we analyzed magnetic data from the CPMN stations. We will present global wave characteristics of Pi 2 s observed at the CPMN stations, show timings of the maximum Pi 2 magnetic energy, examine one-to-one correspondence between the observed $\mathrm{Pi} 2 \mathrm{~s}$ and auroral breakups identified by the Polar satellite, and then draw conclusions in the final section.

\section{Global Characteristics of Pi $2 \mathrm{~s}$}

During the past two decades, many workers have studied Pi 2 magnetic pulsations observed on the ground and in space (see references in Olson, 1999), but the generation and propagation mechanisms of the pulsations are only partly understood. After the international Solar Terrestrial Energy Program (STEP) period (1990-1997), 1-sec magnetic field data from coordinated ground-based network stations made it possible to (1) study magnetospheric processes by distinguishing between temporal changes and spatial variations in the phenomena, (2) clarify global structures and propagation characteristics of magnetospheric variations from higher to 


\section{Circum-pan-Pacific Magnetometer Network}

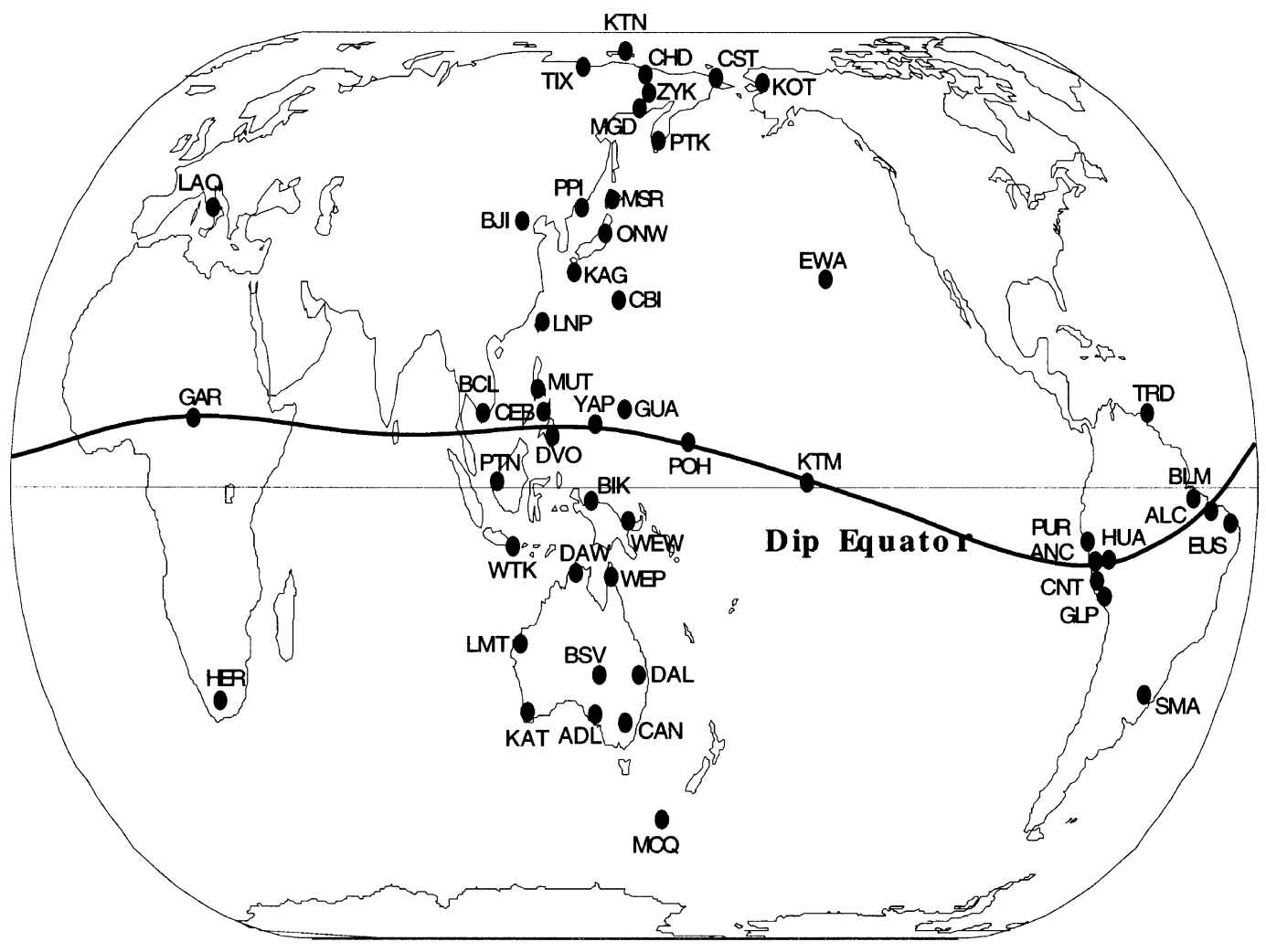

Fig. 1. A station map of the Circum-pan-Pacific Magnetometer Network (CPMN).

equatorial latitudes, and (3) understand the global generation mechanisms of the solar-terrestrial phenomena (see Yumoto and the $210^{\circ} \mathrm{MM}$ Magnetic Observation Group, 1995, 1996).

The latitudinal profiles of Pi 2 amplitudes and phase relations obtained at the CPMN stations in the STEP period imply that Pi 2 pulsations observed on the ground consist of different mode oscillations (see Yumoto et al., 1994; Yumoto and the $210^{\circ} \mathrm{MM}$ Magnetic Observation Group, 1995; Osaki et al., 1996; Shinohara et al., 1997; Li et al., 1998a; Cheng et al., 2000; Li et al., 2000; Uozumi et al., 2000; Solovyev et al., 2000). Recently. Olson (1999) reviewed more than $100 \mathrm{Pi} 2$ papers and concluded that a bouncing of an impulsive field-aligned current (and/or a kinetic Alfvén wave) between the plasma sheet and the auroral ionosphere and an oscillation of the substorm current wedge are detected as high- and mid-latitude Pi 2s, respectively, while a surface wave excited at the plasmapause and a global oscillation in the inner magnetosphere are observed as midand low-latitude Pi 2 s, respectively.

To explain latitude-dependent magnetic pulsations at the higher latitudes, the field line resonance (FLR) was widely believed to be a crucial mechanism in the wave coupling as distant source waves tunnel to excite the field line oscillations in the inner magnetosphere (Chen and Hasegawa, 1974a; Southwood, 1974). Due to the orientation of the major axis of $\mathrm{Pi} 2$ polarization directed to the center of the current wedge, the substorm current wedge is a possible source for mid-latitude Pi 2 pulsations (Lester et al., 1989 and ref- erences there in). Because of the rapid change of the Alfvén speed on a boundary, there may exist surface waves of which the frequency is determined by the Alfven velocities on the both sides of the boundary (Chen and Hasegawa, 1974b). Thus, another source mechanism of mid-latitude Pi 2 pulsations might be associated with the surface waves at the plasmapause. The D-component Pi 2 s having almost maximum amplitudes around $L=3.0$ as shown in figure 1 of Yumoto et al. (1994) might be associated with the surface wave at the plasmapause and/or a localized field-line oscillation just inside the plasmapause. However, by comparing the AMPTE/CCE and ground-based observations, statistical analysis of Pi 2 pulsations in the inner magnetosphere by Takahashi et al. (1995) showed no evidence to support a view that ground Pi 2 pulsations at mid-latitudes $(2<L<5)$ are field-line resonant oscillations in response to the source waves on the auroral zone field line. Hence, more dense ground network observations near the plasmapause with satellite observations are needed to confirm the generation and propagation mechanisms of mid-latitude Pi 2 pulsations.

On the other hand, early observations (e.g., Samson and Rostoker, 1972) reported that Pi 2 pulsations had the characteristics of discrete spectrum, and suggested that there might exist global cavity modes. Stuart (1974) proposed that the secondary amplitude maximum of Pi 2 occurring between $L=2.5$ and $L=4$ is due to plasmaspheric cavity resonances. Moreover, using the magnetometer array from $L=2.38$ to $L=6.23$, Yeoman and Orr (1989) sug- 


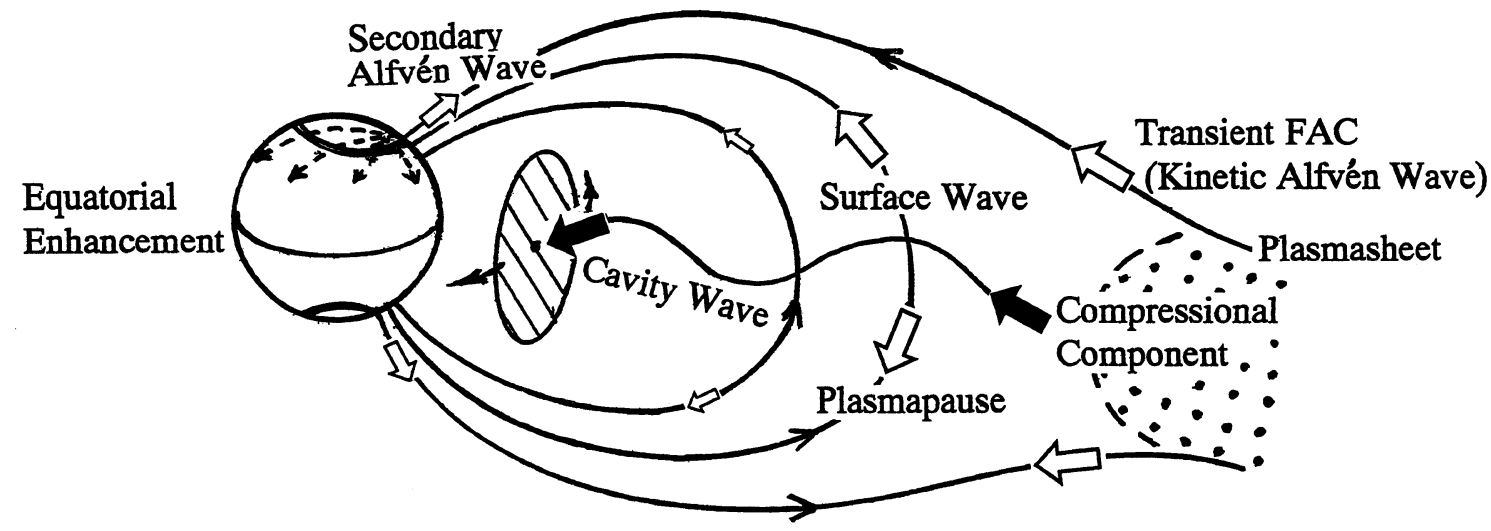

High-lat. Pi 2 - The bouncing of the transient FAC between the plasmasheet and the ionosphere. - Substorm Current Wedge oscillation.

Mid-lat. Pi 2 - Surface wave at the plasmapause.

Low-lat. Pi 2 - Cavity wave in the inner magnetosphere.

Equat. Pi 2 - Transmission of TM-mode Pi 2 in the M-I-A-S system from the auroral latitude.

Fig. 2. A schematic model of Pi 2 magnetic pulsations observed on the ground, consisting of five HM wave components: a bouncing mode of impulsive field-aligned current at the auroral latitude, a substorm current wedge oscillation, a surface wave at the plasmapause, a cavity-like oscillation in the inner magnetosphere, and a transmission of the Pi 2 electric field from the nightside auroral latitude to the dayside equatorial region.
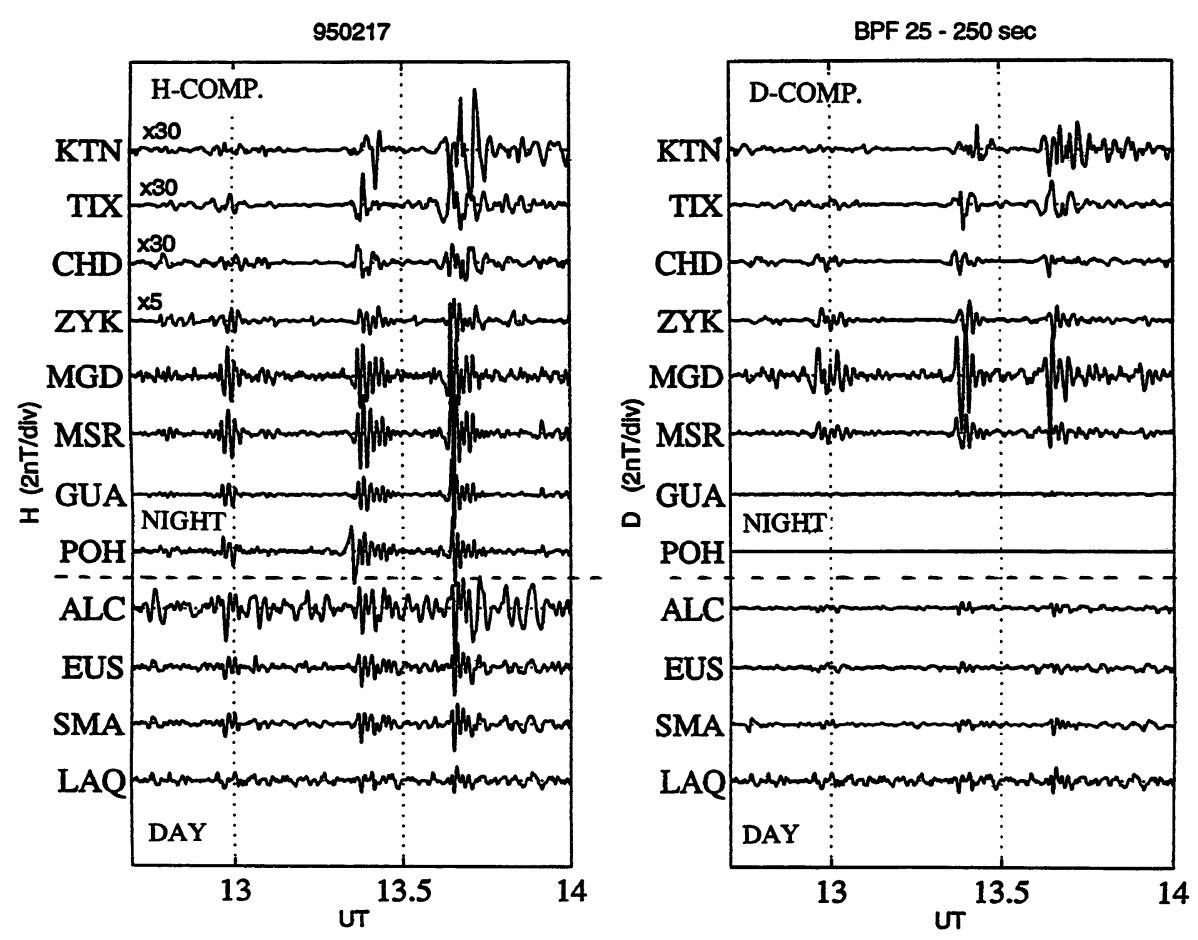

Fig. 3. One example of $\mathrm{H}$ - and D-component, bandpass-filtered (25-250 sec) amplitude-time records of Pi 2 pulsations observed on February 17, 1995, along the $210^{\circ} \mathrm{MM}$ stations from high latitudes to the dip equator at $\mathrm{KTN}\left(\Phi=70.0^{\circ}, L=8.5\right)$, $\mathrm{TIX}\left(65.7^{\circ}, 5.9\right), \mathrm{CHD}^{\circ}\left(64.7^{\circ}, 5.5\right), \mathrm{ZYK}\left(59.6^{\circ}, 3.9\right)$, $\operatorname{MGD}\left(53.5^{\circ}, 2.8\right), \operatorname{MSR}\left(37.3^{\circ}, 1.6\right)$, GUA $\left(5.6^{\circ}, 1.0\right)$, and POH $\left(0.1^{\circ}, 1.0\right)$ in nighttime, at the three Brazilian stations ALC $\left(1.2^{\circ}, 1.0\right)$, EUS $\left(-0.8^{\circ}\right.$, $1.0)$, and SMA $\left(-18.7^{\circ}, 1.1\right)$ in daytime, and at LAQ $\left(36.2^{\circ}, 1.5\right)$ in Italy in daytime.

gested that plasmaspheric cavity resonance is the most likely mechanism for the secondary amplitude maximum of midlatitude Pi 2. Other observations also pointed out that global cavity modes might be responsible for Pi 2 pulsations at very low latitudes and in the inner magnetosphere (Yumoto et al., 1989; Yumoto, 1990; Lin et al., 1991; Sutcliffe and Yumoto, 1991). However, using the AMPTE/CCE satellite,
Takahashi et al. $(1992,1995)$ found that compressional Pi 2 oscillations can be detected only inside a region of $\pm 3 \mathrm{hrs}$ of local midnight and primarily at $L<5$ in the inner magnetosphere. They suggested that the $L$ dependence of the power and phase of these components is such that can be explained by a simple cavity mode resonance with a node in compressional component located near $L=4$. With 

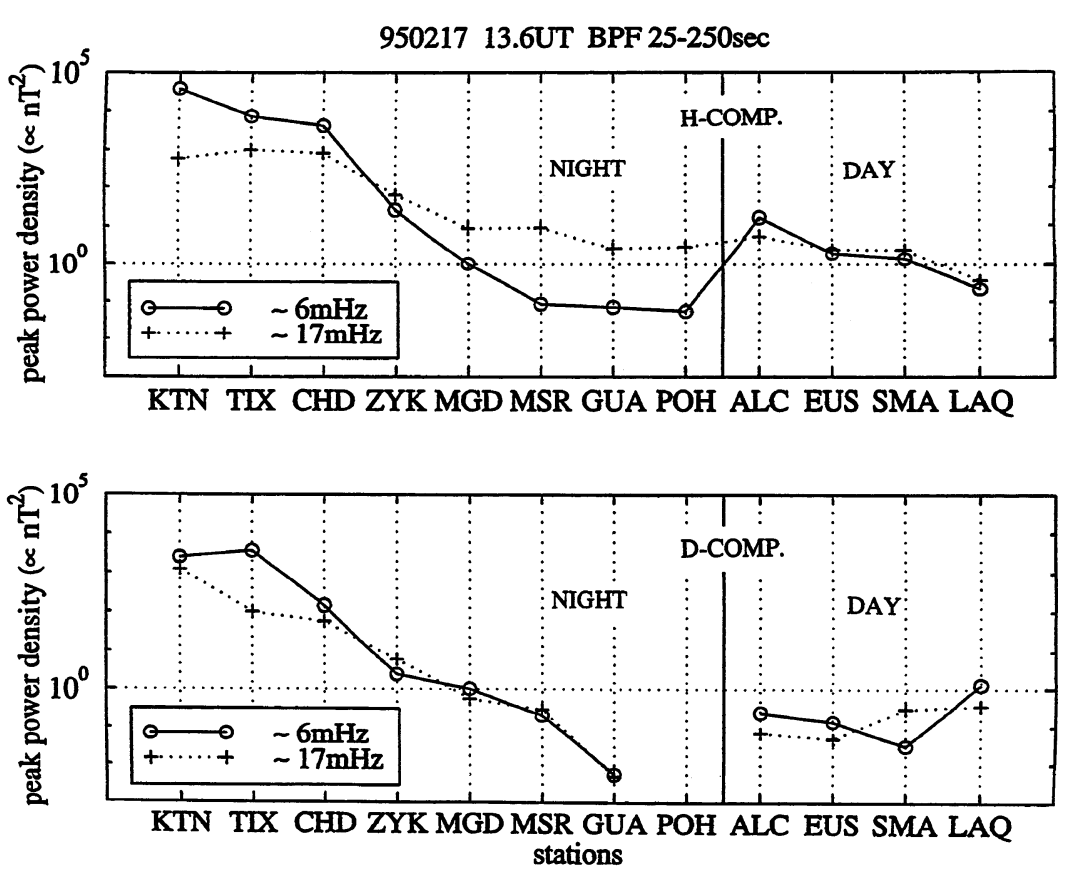

Fig. 4. The spectral peak powers of Pi 2 magnetic pulsations at $6 \mathrm{mHz}$ and $17 \mathrm{mHz}$ from high latitude to the dip equator in nighttime and in daytime. The upper and lower panels show $\mathrm{H}$ - and D-component of the spectral peak power at $6 \mathrm{mHz}$ and $17 \mathrm{mHz}$, respectively.

availability of magnetic fields at the Akebono satellite and ground stations, Osaki et al. (1998) recently confirmed that Pi 2 pulsations propagate to the ground from the magnetotail. By assuming that observed Pi 2 pulsations represent the cavity mode, they found that the escaping Poynting flux could damp a cavity mode oscillation in $\sim 10-20 \mathrm{~s}$, and that the transverse Pi 2 pulsations at the Akebono satellite last for $400 \mathrm{~s}$. Since the nightside ionosphere is not a good reflector and the plasmapause is also neither a good reflector nor a good transmitter, it is not yet well accepted that cavity resonances are driven by impulsive sources out of the plasmasphere. These observations of Takahashi et al. (1992, 1995) and Osaki et al. (1998) may suggest that the lowerlatitude Pi 2 s observed on the ground must be associated with the compresional cavity-like oscillations excited in the longitudinally limited region of \pm 3 hrs of local midnight, where the inner and outer boundaries for the compressional cavity wave between two walls may be the solid Earth of a good reflector and the plasmapause of a not-perfect reflector, respectively. More observations and theoretical studies are needed to further clarify the generation and propagation mechanisms of Pi 2 pulsations at lower latitudes.

Recent results from the CPMN project showed that highlatitude Pi 2s which are mainly caused in association with the westward auroral electrojets, start with a decrease rather than an increase at higher latitude, while low-latitude Pi 2 at the beginning part of positive bay at low latitude start with an increase of H-component magnetic field. We can see almost out-of-phase relationship of H-component Pi 2s between high and low latitudes as shown in figures 1 and 8 of Yumoto et al. (1994). The H-component Pi 2s having almost same wave forms and amplitudes at all lower latitudes as shown in figure 1 of Yumoto et al. (1994) might be associated with sudden formations of the substorm cur- rent wedge and/or the magnetospheric compressional cavity wave. Cheng et al. (2000) found that the ratio of the first four harmonic frequencies of low-latitude Pi 2 pulsations observed at the $210^{\circ} \mathrm{MM}$ stations is consistent with that of plasmaspheric cavity modes simulated in the box model magnetosphere. Shinohara et al. (1997) further indicated that daytime and nighttime Pi 2 pulsations observed at the CPMN stations in the equatorial and low-latitude regions can be explained by invoking an instantaneous penetration of electric field variations from the nightside polar to the dayside equatorial ionosphere, and a direct incidence of compressional oscillations from the nightside inner magnetosphere (e.g. Takahashi et al., 1999), respectively.

From the review of Olson (1999) and the results from the CPMN project, it can be suggested that Pi 2 magnetic pulsations observed on the ground consist of at least five components: (1) a bouncing mode of impulsive FAC at the auroral latitude, (2) a substorm current wedge oscillation, (3) a surface wave at the plasmapause, (4) a cavity-like oscillation in the inner magnetosphere, and (5) a transmission of Pi 2 electric field from the nightside auroral latitude to the dayside equatorial ionosphere, as summarized in Fig. 2. The ground Pi 2 pulsations must be an ensemble of these five modes, which show their own propagations (or timings) and spatial illuminations.

In the following figures, we will demonstrate how Pi 2 pulsations observed at the CPMN stations have complex wave characteristics. Figure 3 shows one example of $\mathrm{H}$ - and D-component, bandpass-filtered (25-250 sec) amplitudetime records of Pi 2 pulsations observed on February 17, 1995 , along the $210^{\circ} \mathrm{MM}$ stations from high latitudes to the dip equator at Kotelnyy (KTN: $\Phi=70.0^{\circ}, L=8.5$ ), Tixe (TIX: 65.7 , 5.9), Chokurdahk (CHD: 64.7 , 5.5), Zyryanka (ZYK: 59.6 , 3.9), Magadan (MGD: 53.5, 2.8), Moshiri 


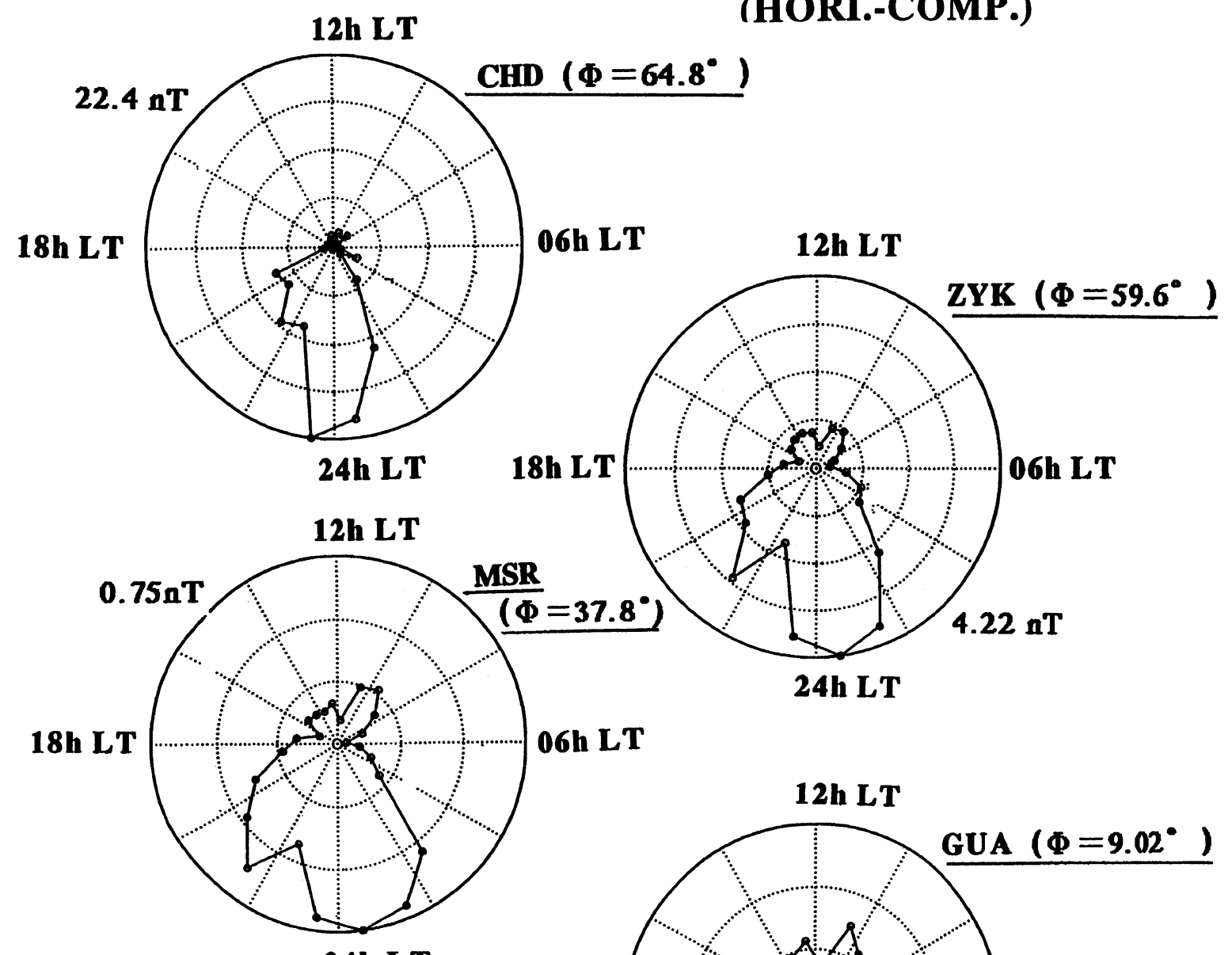

\section{(HORI.-COMP.)}

24h LT

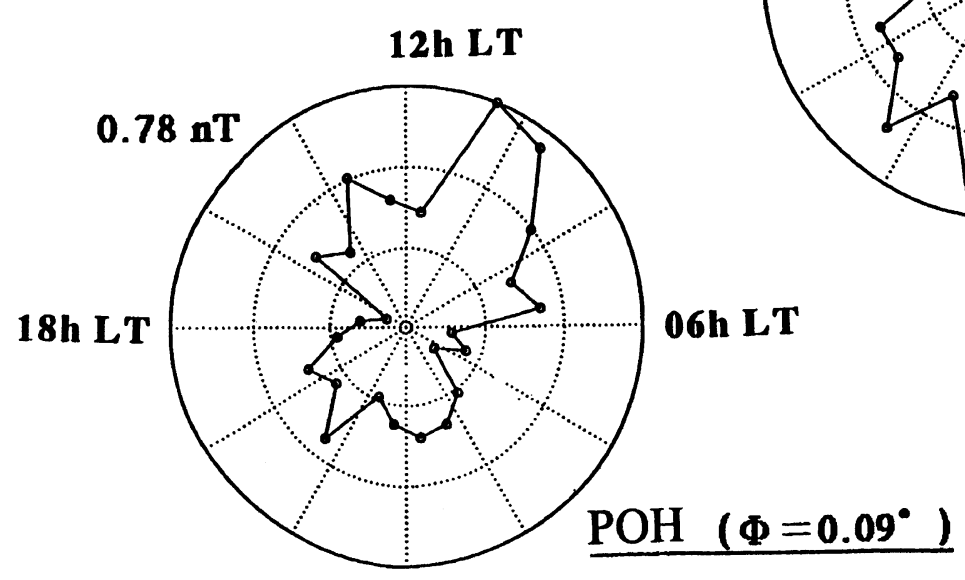

18h LT

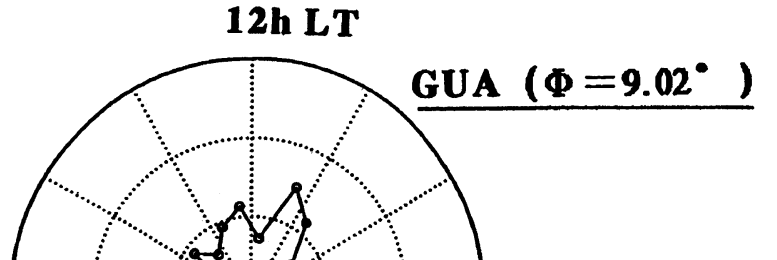

24h LT

Fig. 5. Local time dependence of one-month-averaged horizontal Pi 2 amplitudes of the 249 events observed at CHD at high latitude, ZYK near the plasmapause, MSR at low latitude, GUA near the magnetic equator, and POH at the dip equator. Each solid circle indicates averaged amplitude at each station (cf. figure 2 of Li et al., 2000).

(MSR: $\left.37.3^{\circ}, 1.6\right)$, Guam (GUA: $\left.5.6^{\circ}, 1.0\right)$, and Pohnpei (POH: $\left.0.1^{\circ}, 1.0\right)$ in nighttime, at the three Brazilian stations, Alcantara (ALC: $1.2^{\circ}, 1.0$ ), Eusebio (EUS: $-0.8^{\circ}, 1.0$ ), and Santa Maria (SMA: $\left.-18.7^{\circ}, 1.1\right)$ in daytime, and at Laquila (LAQ: $\left.36.2^{\circ}, 1.5\right)$ in Italy in daytime. The equatorial enhancement of daytime H-component Pi 2s observed at ALC can be explained by using (5) the transmission of Pi 2 elec- tric field from the nightside auroral latitude to the dayside equatorial ionosphere. The higher-frequency H-component Pi 2 s observed at nightside lower latitudes $(1<L<4)$ correspond to (4) the cavity-like oscillation in the inner magnetosphere. The nightside D-component Pi 2s observed around $L=3$ may be (3) the surface wave at the plasmapause and/or a localized field-line oscillation just inside the 
plasmapause. The nighttime higher-latitude Pi 2s at ZYK, TIX, and CHD must be associated with (2) the substorm current wedge oscillation. The nighttime Pi $2 \mathrm{~s}$ with lowfrequency component at $\mathrm{KTN}$ at $\Phi=70.0^{\circ}, L=8.5$ may have characteristics of a bouncing mode of impulsive fieldaligned current at the auroral latitude. It is noteworthy that the low-frequency component of Pi 2 can be seen predominantly at higher latitudes in nighttime and near the equator in daytime, while the higher-frequency component can be seen predominantly at mid- and low-latitudes in nighttime.

We calculated the power spectral density $\left(\mathrm{nT}^{2} / \mathrm{Hz}\right)$ of the Pi 2 event observed at 13:35-13:45 UT at those stations as shown in Fig. 3, and found two predominant components at frequencies of $6 \mathrm{mHz}$ and $17 \mathrm{mHz}$. Figure 4 shows the peak power at frequencies of 6 and $17 \mathrm{mHz}$ as a function of the stations from high latitude to the dip equator in nighttime, and in daytime. The upper and lower panels show $\mathrm{H}-$ and D-component peak power variations, respectively. The lowfrequency $\mathrm{H}$ component is predominant at high latitudes in nighttime and at equatorial latitude in daytime, while the high-frequency component is larger than the low-frequency component at lower latitudes in nighttime. The low- and high-frequency D components show comparable power at lower latitudes in nighttime. Li et al. (1998a) statistically estimated the spectral power of each of $249 \mathrm{Pi} 2$ events in February 1995, made averaged predominant frequencies of the events in each hour, and then plotted the hourly averaged frequency as a function of local time at the $210^{\circ} \mathrm{MM}$ stations. At the high-latitude station $\operatorname{CHD}\left(\Phi=64.7^{\circ}\right)$, the averaged predominant frequency is between 8 and 12 $\mathrm{mHz}$ with no significant maximum or minimum. At the midand low-latitude stations, a maximum frequency of about 15 $\mathrm{mHz}$ can be seen around local midnight, and a lower frequency of about $10 \mathrm{mHz}$ in the evening hours. At the equatorial station $\mathrm{POH}$, the frequency shows the same local time dependence and values as the mid- and low-latitude components in nighttime, while in daytime (06-18 hr LT) the averaged predominant frequency is between 10 and $12 \mathrm{mHz}$, which is in the same frequency range as the auroral-latitude Pi 2s (see figure 5 of Li et al., 2000).

Each diagram in Fig. 5 shows a local time profile of onemonth-averaged horizontal amplitudes of the $249 \mathrm{Pi} 2$ events observed at $\mathrm{CHD}\left(\Phi=64.7^{\circ}\right)$ at high latitude, ZYK $\left(59.6^{\circ}\right)$ near the plasmapause, MSR $\left(37.3^{\circ}\right)$ at low latitude, GUA $\left(5.6^{\circ}\right)$ near the magnetic equator, and $\mathrm{POH}\left(0.1^{\circ}\right)$ at the dip equator. Each solid circle indicates an averaged maximum amplitude of $22.4 \mathrm{nT}$ at CHD, $4.2 \mathrm{nT}$ at ZYK, $0.75 \mathrm{nT}$ at MSR, $0.39 \mathrm{nT}$ at GUA, and $0.78 \mathrm{nT}$ at POH. It is noteworthy that high-latitude Pi 2 amplitudes show a maximum, appearing in the narrow local midnight sector of 23-01 hr LT, while at middle, low, and near-equatorial latitudes, two maximum amplitudes appear around local midnight and around $21 \mathrm{hr}$ LT. The secondary peak at $21 \mathrm{hr}$ LT is significant, because it can be obtained for a different one-month-averaged data set. At the dip equator, the equatorial enhancement of Pi 2 amplitudes can be seen around $10 \mathrm{hr}$ LT. These diagrams and Fig. 4 suggest that at least two dominant frequency components of Pi 2 pulsations appear at high latitude in the narrow local midnight sector of 23-01 hr LT and in the inner magnetosphere of the midnight sector from $21 \mathrm{hr}$ to $03 \mathrm{hr}$ LT.

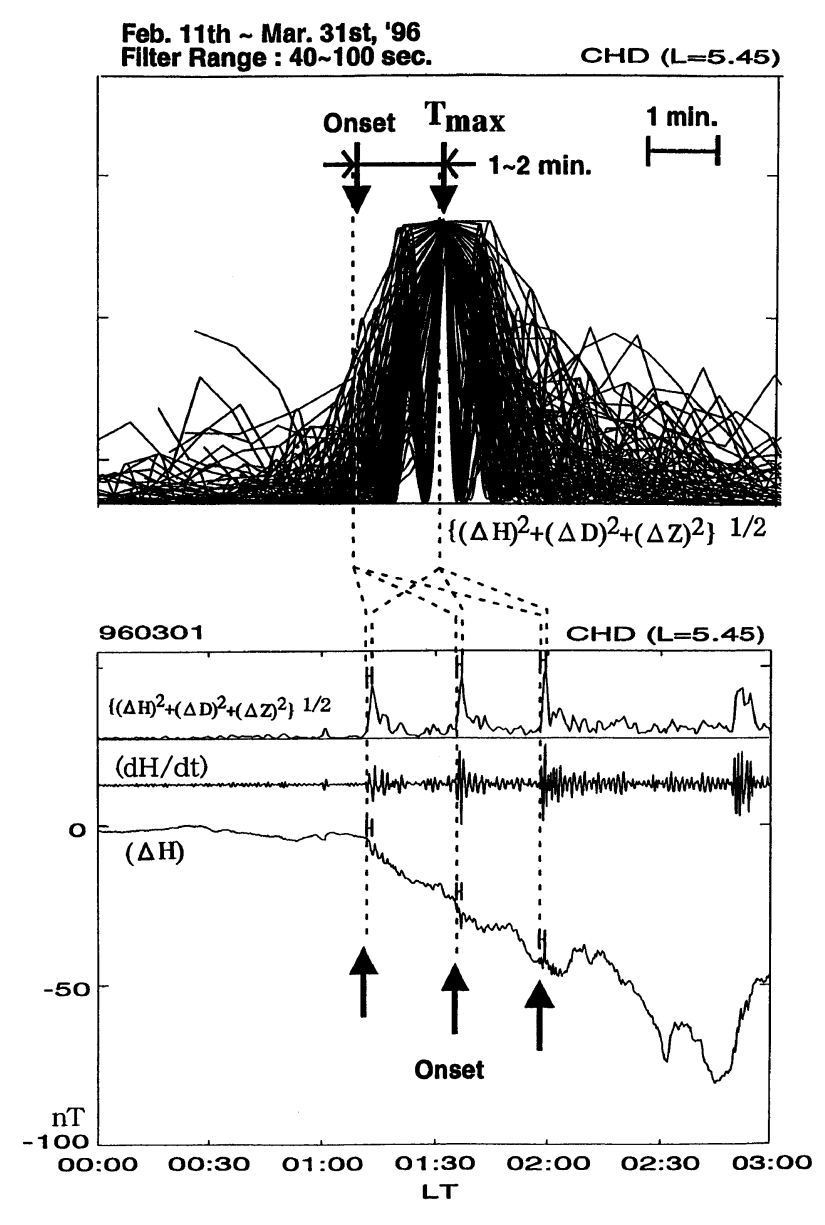

Fig. 6. (Bottom) Example of the calculated amplitude of Pi 2 magnetic energy $(\Delta H)^{2}+(\Delta D) 2+(\Delta Z)^{2} \mu_{o}$, amplitude-time records of $d H / d t$, and $\Delta H$ variations observed at CHD $(L=5.5)$ on March 1, 1996. (Top) One- to two-minute time difference between Pi 2 onsets and the timing of maximum magnetic energy in the superposed plots, during the interval from February 11 to March 31, 1996 (see Uozumi, 2000).

There are no existing theories that explain why the second amplitude peak appears around $21 \mathrm{hr}$ LT and why the equatorial amplitude enhancement has a maximum around $10 \mathrm{hr}$ LT. But, from the global characteristics as shown in Figs. 2 through 5, the high-latitude Pi 2 predominantly appearing in the midnight sector, the mid- and low-latitude Pi $2 \mathrm{~s}$ in the 21-02 hr LT sector, and the dayside equatorial enhancement around $10 \mathrm{hr}$ LT may be respectively interpreted by using the substorm current wedge oscillation, a cavity-like compressional oscillation in the nightside inner magnetosphere, and the transmission of electric fields in the magnetosphereionosphere-atmosphere-solid Earth system from the nightside auroral latitude to the dayside equator.

\section{Timings of the Maximum Pi 2 Wave Energy}

Sometimes it is difficult to identify the onset time of Pi 2 s, because of a gradual increase in the amplitudes. The ground Pi 2 pulsations are an ensemble of the five modes as shown in Fig. 2, which show their own propagations (or timings) and spatial illuminations. Although it is not easy to know propagation mechanisms of the five modes by using the limited ground stations, Uozumi et al. (2000) newly defined a Pi 2 magnetic energy variations as 


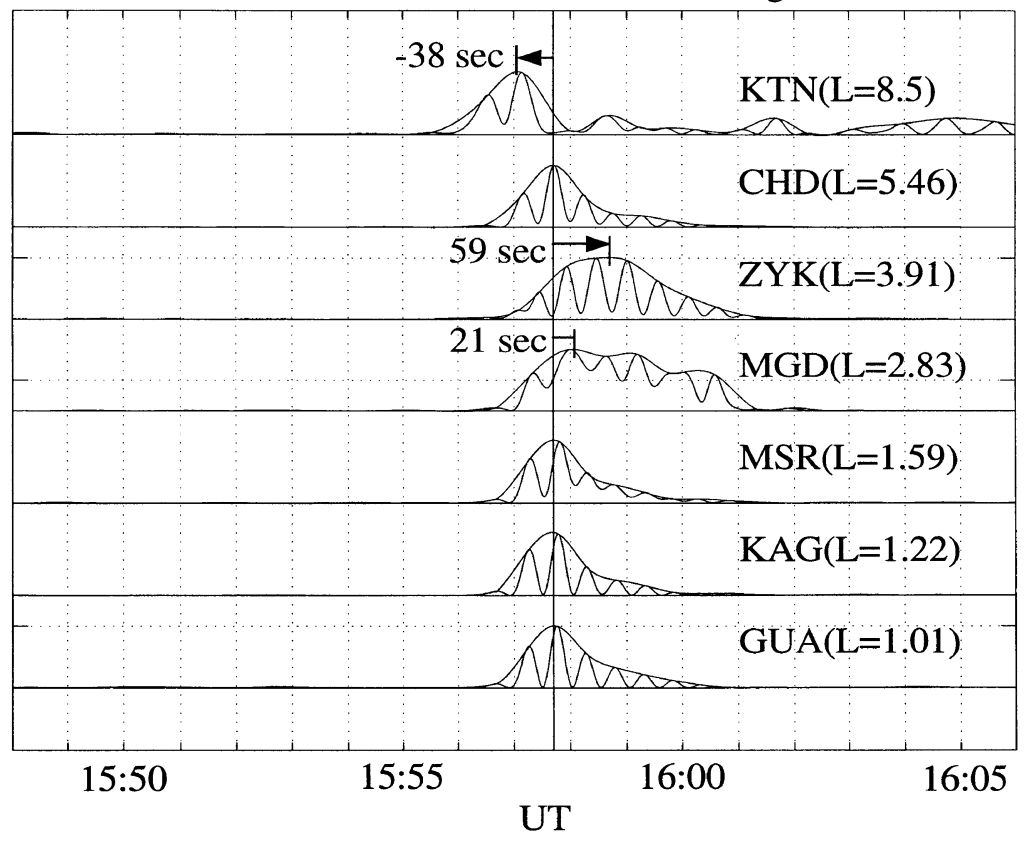

Fig. 7. Latitudinal profile of timings of the maximum Pi 2 magnetic energy $(\Delta H)^{2}+(\Delta D)^{2}+(\Delta Z)^{2} \mu_{o}$ observed at 15:55 UT on January 7, 1995 , along the $210^{\circ} \mathrm{MM}$ from the auroral stations at KTN and CHD, through the plasmapause near ZYK, to the mid- and low-latitudes at MGD, MSR, and KAG, and to the equatorial region near GUA (figure 1 of Uozumi et al., 2000).

$(\Delta H)^{2}+(\Delta D)^{2}+(\Delta Z)^{2} / \mu_{o}$, and then compared timings when the amplitudes of Pi 2 magnetic energy became maximum. The magnetic energy carried by MHD waves is expressed by $(\Delta H)^{2}+(\Delta D)^{2}+(\Delta Z)^{2} \mu_{o}$. That is, the variation of the magnetic energy is proportional to the squared amplitude of magnetic variations. When using the magnetic energy perturbation on the ground, the arrival time of Pi 2 magnetic energy can be determined more accurately without depending on phase or polarization changes among the stations. Figure 6 shows one example of propagation characteristics of Pi 2 s (or timings of Pi 2 onsets) observed at globally separated CPMN stations. The bottom panel indicates the calculated Pi 2 magnetic energy amplitude, amplitudetime records of $d H / d t$, and $\Delta H$ variations observed at CHD ( $L=5.5$ ) on March 1, 1996. As shown statistically in the top panel, a one- to two-minute time difference between the Pi 2 onsets and timings of the maximum magnetic energy can be seen in the superposed plots during the interval from February 11 to March 31, 1996.

Figure 7 shows the latitudinal profile of timings of the maximum Pi 2 magnetic energy observed at 15:55 UT on January 7,1995 , along the $210^{\circ} \mathrm{MM}$ from the auroral stations at $\operatorname{KTN}\left(\Phi=70.0^{\circ}, L=8.5\right)$ and $\operatorname{CHD}\left(64.7^{\circ}, 5.5\right)$, through the plasmapause near ZYK $\left(59.6^{\circ}, 3.9\right)$, to the midand low-latitudes at $\operatorname{MGD}\left(53.5^{\circ}, 2.8\right), \operatorname{MSR}\left(37.3^{\circ}, 1.6\right)$, and Kagoshima (KAG: $25.1^{\circ}, 1.2$ ), and to the equatorial region near GUA $\left(5.6^{\circ}, 1.0\right)$. The amplitudes of Pi 2 wave energy in the figure have been normalized. The solid vertical line is a time when the Pi 2 magnetic energy became maximum at Guam. At ZYK near the plasmapause, we can see an 59-second time delay with respect to the lowlatitude Pi 2s. On the other hand, at KTN higher-latitude
Pi 2 leads those at CHD and the low-latitude stations by about 40 seconds. These time differences at higher latitude and near the plasmapause can be explained by using the difference between the times-of-flight of Alfvén and fast magnetosonic waves, which propagate along and across, respectively, the ambient magnetic field from the magnetospheric equator of each station to the ionosphere (see Uozumi et al., 2000). Where a compressional Pi 2 source wave around $L=9$ in the magnetotail was assumed to propagate across the ambient field, and couple into bouncing oscillations (i.e. Alfvén wave) at the auroral latitude and near the plasmapause, which may be observed as higher-latitude Pi 2 and a surface wave-type mid-latitude Pi 2 , respectively.

The left, middle, and right panels of Fig. 8 obtained by Uozumi (2000) show three examples of longitudinal time differences of the maximum Pi 2 magnetic energy observed in the high-latitude region at $\operatorname{KTN}\left(\Phi=70.0^{\circ}, \Lambda=\right.$ $\left.201.0^{\circ}\right)$, TIX $\left(65.7^{\circ}, 196.9^{\circ}\right)$, and CHD $\left(64.7^{\circ}, 212.1^{\circ}\right)$ in Siberia, and Kotzubue (KOT: $64.5^{\circ}, 249.7^{\circ}, L=5.40$ ) in Alaska. The figure shows time differences in the premidnight, midnight, and post-midnight sectors. It is found that Pi $2 \mathrm{~s}$ at $\mathrm{KTN}\left(\Phi=70.0^{\circ}\right)$ tend to lead those at highlatitude stations KOT, TIX, and CHD at $\Phi \sim 65.0^{\circ}$ by about 40 seconds in all sectors. It is also noteworthy that a westward time delay of high-latitude Pi 2 s from the midnight station KOT to the pre-midnight station TIX can be seen in the pre-midnight sector, while an eastward time delay from the midnight station TIX to the post-midnight station KOT can be seen in the post-midnight sector.

Uozumi (2000) also analyzed timings of the Pi 2 magnetic energy observed at the low-latitude stations at KAG $\left(\Phi=25.1^{\circ}, \Lambda=202.2^{\circ}\right.$ ) in Japan and Ewa Beach (EWA: 
PREMIDNIGHT

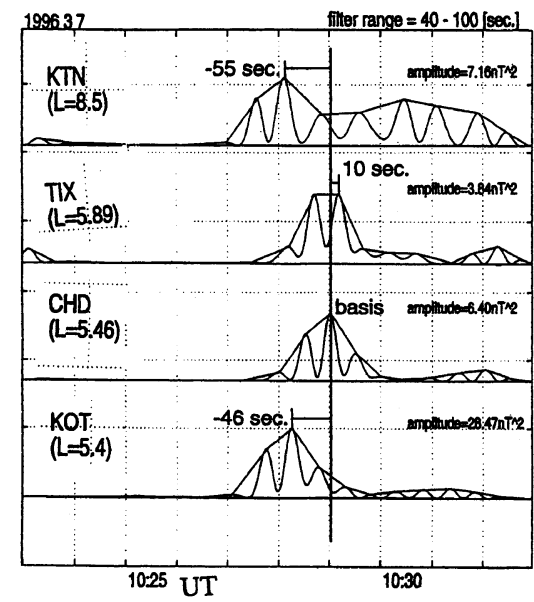

MIDNIGHT

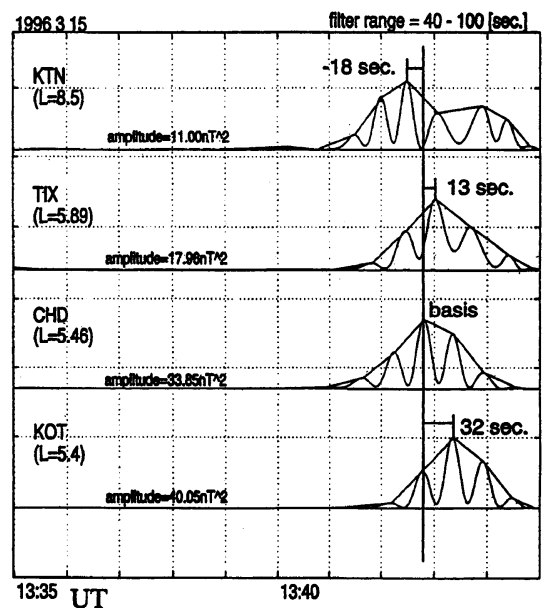

POSTMIDNIGHT

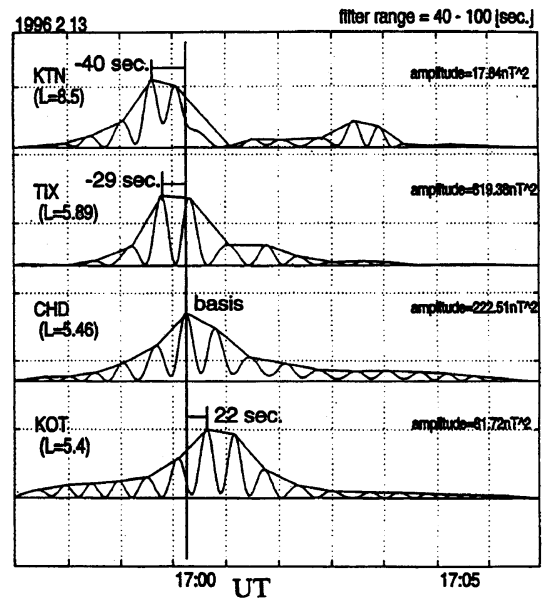

Fig. 8. Three examples of longitudinal time differences of the maximum Pi 2 magnetic energy observed in the high-latitude region at $\mathrm{KTN}\left(\Phi=70.0^{\circ}\right.$, $\left.\Lambda=201.0^{\circ}\right)$, TIX $\left(65.7^{\circ}, 196.9^{\circ}\right)$, and CHD $\left(64.7^{\circ}, 212.1^{\circ}\right)$ in Siberia, and Kotzubue (KOT: $\left.64.5^{\circ}, 249.7^{\circ}, L=5.40\right)$ in Alaska. Time differences are shown in the pre-midnight (left), midnight (middle), and post-midnight (right) sectors (cf. Uozumi, 2000).
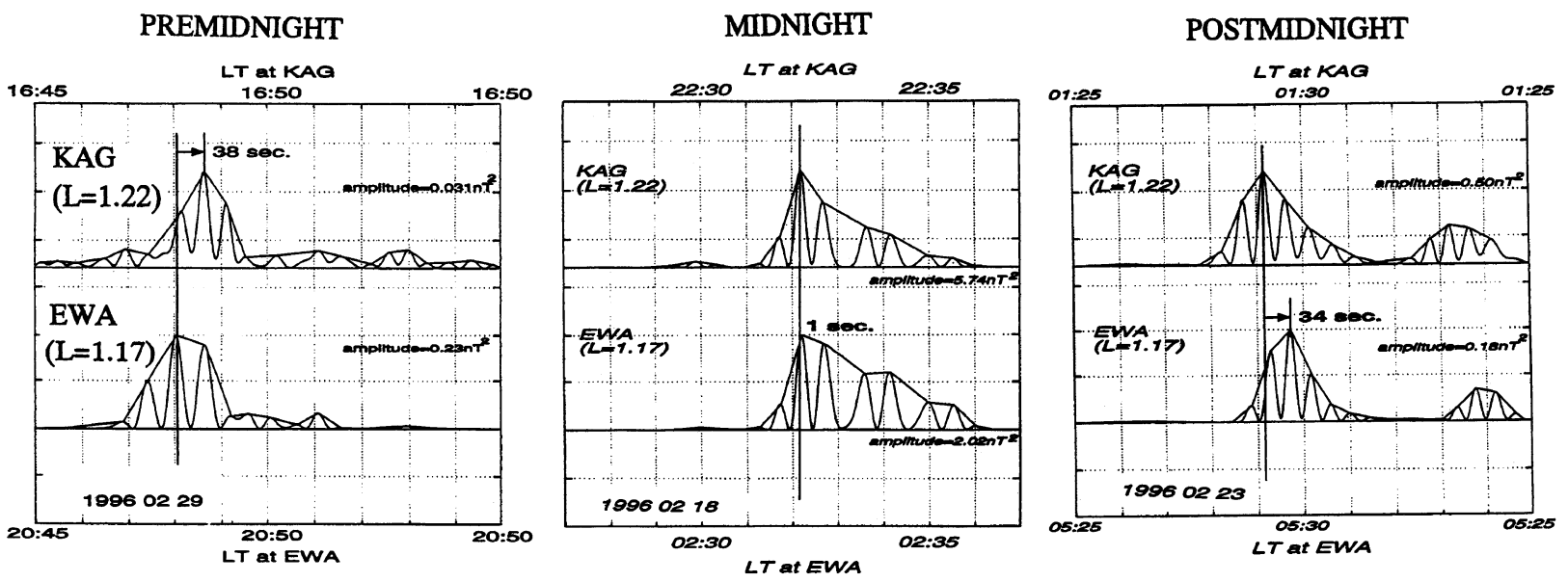

Fig. 9. Timings of the Pi 2 magnetic energy observed at the low-latitude stations KAG in Japan and EWA in Hawaii. Timings are shown for the pre-midnight (left), midnight (middle), and post-midnight (right) sectors (cf. Uozumi, 2000).

$22.7^{\circ}, 269.4^{\circ}$ ) in Hawaii as shown in Fig. 9. The figure indicates data for the pre-midnight, midnight, and post-midnight sectors. The low-latitude Pi 2 s show a westward time delay from the midnight-side station EWA to the duskside station $\mathrm{KAG}$, no time difference when these stations are located in the local midnight sector of $22 \mathrm{hr}$ to $03 \mathrm{hr} \mathrm{LT}$, and an eastward time delay from the midnight-side station KAG to the dawnside station EWA.

83 Pi 2 events were statistically examined for a 50-day period from February 11 to March 31, 1996, and it is found that high-latitude Pi 2s show apparent westward and eastward propagation in the pre-midnight and post-midnight sector, respectively. The low-latitude Pi 2 s also show apparent eastward propagation in the dawnside, but an unclear, mixed nature in the duskside.

\section{One-to-one Correspondence between Pi 2s and Auroral Breakups}

We next discuss on one-to-one correspondence between Pi 2s observed at the CPMN stations and auroral breakups identified by the Polar satellite. Li et al. (1998b) have examined the one-to-one correspondence in detail. In this section we will briefly summarize their results. The upper and lower panels of Fig. 10 show the percentage of auroral breakups (identified by the Ultraviolet Imager (UVI) on board the ISTP Polar satellite) that have associated Pi $2 \mathrm{~s}$ observed at a single low-latitude station $\operatorname{MSR}\left(\Phi=37.3^{\circ}, L=1.6\right)$, and at MSR or the high-latitude station CHD (64.7 $\left.7^{\circ}, 5.5\right)$, respectively. The 108 auroral breakups were identified between latitudes $60^{\circ} \mathrm{N}$ and $73^{\circ} \mathrm{N}$, and between local times 20 $\mathrm{hr}$ and $03 \mathrm{hr}$ (see Liou et al., 1998), and are plotted at hourly intervals in the panels. If we use a single low-latitude magnetometer station, we can see a one-to-one correspondence of only $62 \%$ (with no restriction in local time of the ground station) or $79 \%$ (when the ground station is in the nighttime sector between $20 \mathrm{hr}$ and $03 \mathrm{hr}$ LT) between the auroral breakups and the low-latitude Pi 2s. But if the single station is located in the midnight sector from 23 to $01 \mathrm{hr} \mathrm{LT}$, we can see a $100 \%$ one-to-one correspondence. If we use the high- and low-latitude two-magnetometer stations, we 


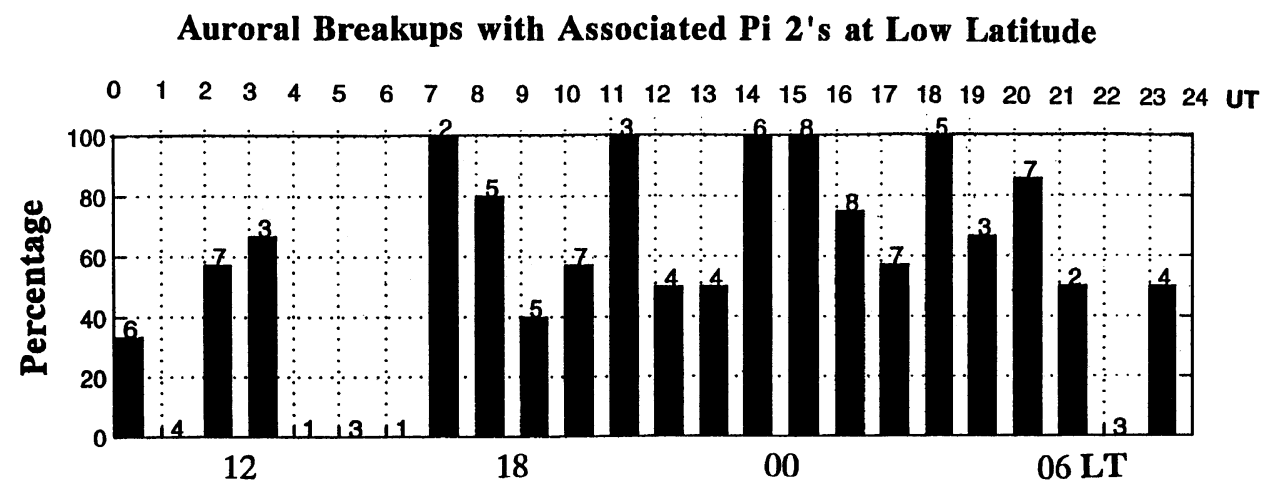

Auroral Breakups with Associated Pi 2's at High \& Low Latitudes

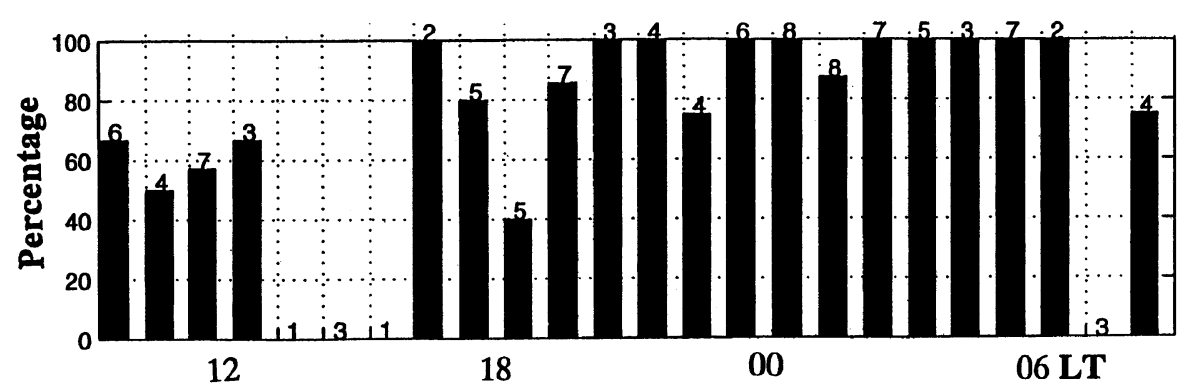

Fig. 10. 108 auroral breakups identified by the POLAR satellite displayed in hourly intervals. The number of auroral breakup events is shown in each hour bin. (Top) Percentage of auroral breakups with associated Pi 2s observed at the low-latitude station MSR. (Bottom) Percentage of auroral breakups with associated Pi 2s observed at MSR or the high-latitude station CHD (Li et al., 1998b).

can obtain a one-to-one correspondence of $78 \%$ (with no restriction in local time) or $95 \%$ (when the ground stations are in the nighttime sector between $20 \mathrm{hr}$ and $03 \mathrm{hr}$ LT) between the auroral breakups and the Pi 2 pulsations.

Figure 11 shows three examples of magnetic substorms with Pi 2 pulsations observed at the $210^{\circ} \mathrm{MM}$ stations at $\mathrm{KTN}\left(\Phi=70.0^{\circ}, L=8.5\right)$, $\mathrm{TIX}\left(65.7^{\circ}, 5.9\right), \mathrm{CHD}\left(64.7^{\circ}\right.$, 5.5), MGD $\left(53.5^{\circ}, 2.8\right), \operatorname{MSR}\left(37.3^{\circ}, 1.6\right), \operatorname{LNP}\left(13.8^{\circ}\right.$, 1.06), and EWA $\left(22.7^{\circ}, 1.17,+4 \mathrm{hr}\right.$ LT $)$ in the pre-midnight ( $\sim 22 \mathrm{hr} \mathrm{LT})$, midnight $(\sim 00 \mathrm{hr}$ LT), and post-midnight $\left(>01 \mathrm{hr}\right.$ LT) sectors of the $210^{\circ} \mathrm{MM}$. Pi 2 pulsations at 1504 UT in the midnight sector were observed at all the stations from high- to low-latitudes, whereas Pi 2 s at 1254 and 1618 UT outside the midnight sector (23-01 hr LT) did not appear at lower latitudes. It is noteworthy that when the meridional chain stations are located in the midnight sector of 23-01 LT, we can see Pi 2 pulsations from high- to lowlatitudes, while when the chain stations are located outside the midnight sector, we sometimes miss low-latitude Pi 2 s. The not-perfect one-to-one correspondence between the auroral breakups and the Pi 2 pulsations as shown in Fig. 10 can be explained by the observational fact that Pi 2 pulsations outside the midnight sector of 23-01 hr LT sometimes cannot appear at lower latitudes.

Further study is needed to clarify why Pi 2 s sometimes do not appear at lower latitudes outside the midnight sector. This phenomenon may be dependent on the magnitude of the substorm, the location of auroral breakups, the generation mechanism of cavity-like oscillations in the nighttime inner magnetosphere, the propagation mechanism of Pi 2 from high to lower latitudes, etc.
In order to investigate the occurrence region of Pi 2 and its propagation mechanisms in the magnetosphere, Uozumi (2000) analyzed ground magnetometer data from the CPMN four stations at Kotel'nyy (KTN: MLAT $=69.94^{\circ}$, MLON $\left.=201.02^{\circ}\right)$, Tixie (TIX: 65.67, $196.88^{\circ}$ ), Chokurdakh (CHD: $64.67^{\circ}, 212.12^{\circ}$ ) and Kotzebue (KOT: $\left.64.52^{\circ}, 249.72^{\circ}\right)$. The times when the Pi 2 magnetic energy becomes maximum at each station were compared among the stations, and the ratios of the maximum energy among the stations were also compared. From the analyzed results, it is found that high-latitude $\mathrm{Pi} 2 \mathrm{~s}$ (having the maximum magnetic energy around $\sim 22.5$ MLT) show apparent eastward and westward propagation from the center of $\sim 22.5$ MLT. In consideration of the observed time delays among the stations and numerical estimation of Alfvén transit time from a point in the magnetosphere to the ground station, Uozumi (2000) suggested that high-latitude Pi 2s must be generated around Xsm $=-9 R_{E}$ and 22.5 MLT on the equatorial plane in the magnetotail.

On the other hand, Liou et al. (2001a) recently used Polar UVI and Wind observations to study the location of 648 well-defined Northern Hemisphere auroral breakups (substorm onsets) in response to interplanetary magnetic field (IMF) orientation and season. The mostly likely onset location is found to be at $2230 \mathrm{MLT}$ and $67^{\circ}$ magnetic latitude with half-maximum widths of $3 \mathrm{hrs}$ of MLT and $2^{\circ}$ magnetic latitude, respectively. The onset longitude depends on season and IMF By. In summer, substorms tend to occur in the early evening at 2200 MLT, wherese in winter they tend to occur near midnight at $\sim 2300$ MLT. It is noteworthy that the location of auroral breakups identified statistically 

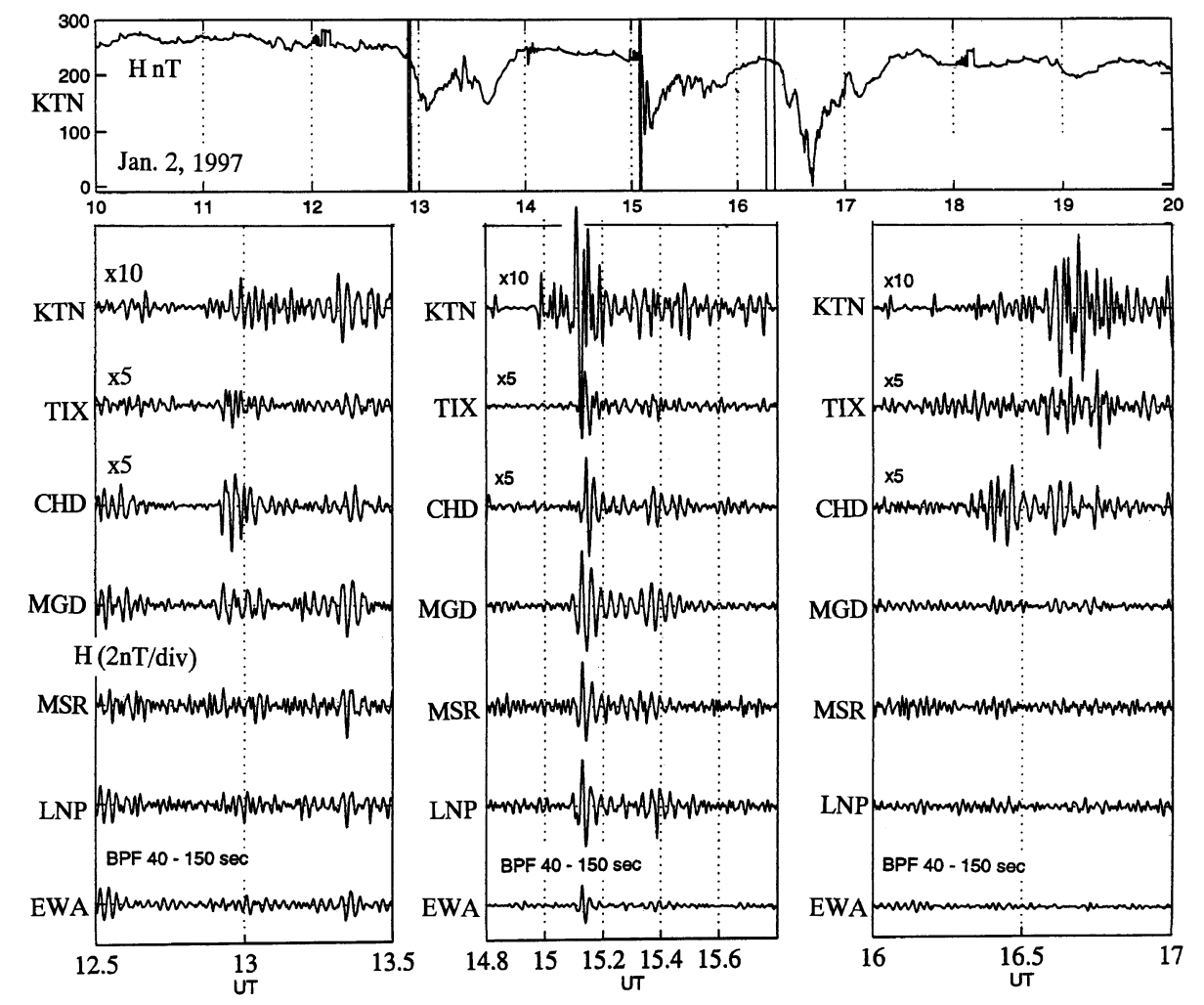

Fig. 11. Three examples of small substorms with Pi 2 pulsations observed by the $210^{\circ} \mathrm{MM}$ stations at KTN, TIX, CHD, MGD, MSR, LNP, and EWA (+4 $\mathrm{hr}$ LT) in the pre-midnight ( $\sim 22 \mathrm{hr}$ LT), midnight ( $\sim 00 \mathrm{hr} \mathrm{LT})$, and post-midnight ( $>01 \mathrm{hr} \mathrm{LT})$ sectors of the $210^{\circ} \mathrm{MM}$. (Top) Amplitude-time records of the H-component magnetic field at KTN during 10-20 hr UT on January 2, 1997. (Bottom) Pi 2 pulsations observed at the $210^{\circ}$ MM stations at 1224 UT in the pre-midnight, 1504 UT in the midnight, and 1618 UT in the post-midnight sector.

by the Polar satellite is consistent with the estimated location where high-latitude Pi 2 s are generated in the magnetotail (Uozumi, 2000). However, the high-latitude Pi 2s have a maximum amplitude in the narrow local midnight sector of 23-01 hr LT as shown in Fig. 5, while at middle, low, and near-equatorial latitudes, two maximum amplitudes appear around local midnight and around $21 \mathrm{hr}$ LT. The amplitude maximum around the local midnight must be associated with the formation of the SCW (McPherron et al., 1973), while the other maximum around $21 \mathrm{hr}$ LT might be associated with the onset location of auroral breakups around 2230 MLT (Liou et al., 2001a).

Finally, Li et al. (1998b) examined the time difference between the auroral breakups identified by the Polar satellite and the Pi 2 onsets identified by using high-resolution data from the $210^{\circ} \mathrm{MM}$ stations. The time resolution of the auroral image of the Polar satellite is 38 seconds and Pi 2's period is 40 to 150 seconds; therefore the accuracy of the time difference is $1 \mathrm{~min}$. The upper panel of Fig. 12 shows the time difference between the auroral breakups and 67 associated Pi 2 events observed at the single low-latitude station MSR $\left(\Phi=37.3^{\circ}, L=1.6\right)$. The lower panel shows a histogram of the time difference in 1-minute bins. From a comparison of the onset times of low-latitude Pi 2 pulsations at the $210^{\circ} \mathrm{MM}$ station and auroral breakups at the Polar satellite, it is found that $66 \%$ of low-latitude Pi $2 \mathrm{~s}$ occur within $1 \mathrm{~min}$ of the auroral breakups, and $85 \%$ occur within $2 \mathrm{~min}$.

Liou et al. (2001b) compared the onset of dispersionless energetic particle injections, observed as a sudden increase of energetic electron and ion flux on a timescale of $\sim 1 \mathrm{~min}$ at $L=6.6$, with the start of auroral breakups by the LANL satellites. They suggested that the averaged lag time for particle injections compared to the auroral breakups is 1.8 min with a standard deviation of $2.5 \mathrm{~min}$, and concluded that particle energization must take place in the magnetotail $\sim 1$ min earlier than the start of the explosive auroral substorm onset. With respect to the relationship of the onset time of low-latitude Pi $2 \mathrm{~s}$ with the auroral breakups as shown in Fig. 12, the comparison between the onset of energetic particle injections at $L=6.6$ and the start of the auroral breakups (Liou et al., 2001b), and the Alfvén transit time ( $\sim 1 \mathrm{~min}$ ) of Pi 2 waves from the magnetotail around 9 $R_{E}$ into the polar ionosphere, we suggest that the particle energization and the Pi 2 generation may take place almost at the same time in the magnetotail.

\section{Summary and Conclusions}

From analyses of magnetic field data from the CPMN stations, the following observational results were obtained:

(1) Pi 2 magnetic pulsations observed on the ground are an ensemble of various hydromagnetic modes excited at high, middle, low, and equatorial latitudes as shown in Fig. 2. Each mode exhibits its own propagation (timing) and spatial illumination.

(2) There are apparent longitudinal propagation and latitudinal time delays of the maximum $\mathrm{Pi} 2$ magnetic energy among the CPMN stations, suggesting the generation 

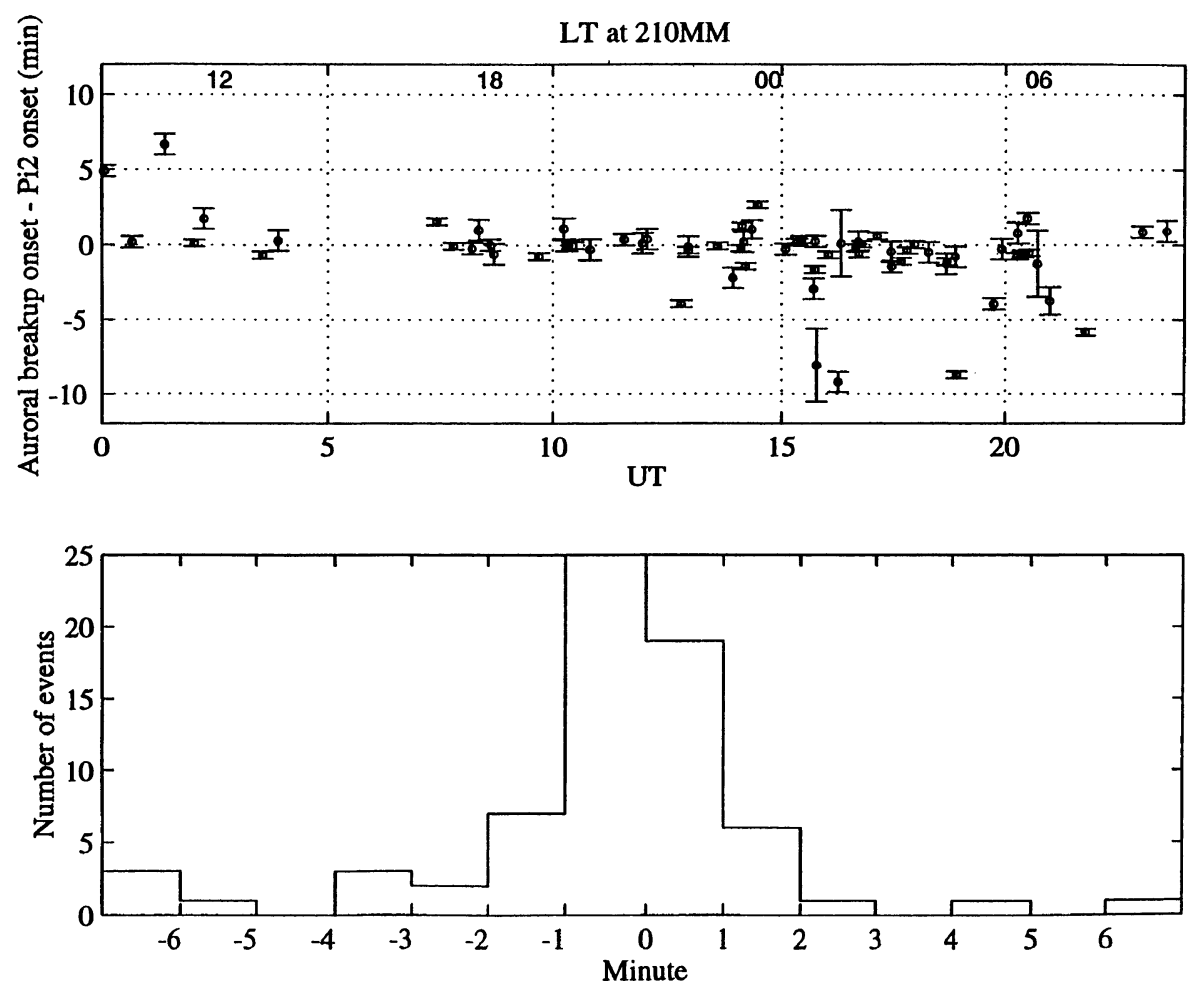

Fig. 12. (Top) Time difference between auroral breakup events in Fig. 10 and 67 associated Pi 2 events observed at low latitude (MSR), where a negative time difference means a delayed Pi 2. (Bottom) A histogram of the time difference in 1-minute bins (Li et al., 1998b).

of high-latitude Pi 2s around geocentric distance at Xsm = $-9 R_{E}$ and 22.5 MLT on the equatorial plane in the magnetotail.

(3) When a single low-latitude station is located in the sectors of 00-24 hr LT, 20-03 hr LT, and 23-01 hr LT, respectively, $62 \%, 79 \%$, and $100 \%$ of auroral breakups identified by the Polar satellite have associated Pi 2s (see Fig. 10). $66 \%$ of the low-latitude Pi $2 \mathrm{~s}$ occur within $1 \mathrm{~min}$ of the auroral breakups, and $85 \%$ occur within 2 min (see Fig. 11).

From these observational results, when a single ground station is located at the midnight sector of 23-01 hr LT, almost $100 \%$ one-to-one correspondence can be expected between the auroral breakups and low-latitude Pi 2s. But when the ground station is located outside the midnight sector, we can see only a $60-80 \%$ one-to-one correspondence between Pi 2 onsets and auroral breakups with a 1-2 min time delay . The Pi 2 s are still a good indicator of substorm onsets, but they should be used with care.

Further observational and theoretical works are needed to clarify why Pi 2 s sometimes do not appear at lower latitudes outside the midnight sector (23-01 hr LT), as shown in Fig. 11. This phenomenon may be dependent on the magnitude of the substorms, the location of auroral breakups, the generation mechanism of cavity-like oscillations in the nighttime inner magnetosphere, the propagation mechanism of Pi 2s from high to lower latitudes, etc. There are no existing theories that explain why the second amplitude peak appears around $21 \mathrm{hr}$ LT at mid- and low-latitudes, and why the equatorial amplitude enhancement has a maximum around $10 \mathrm{hr}$ LT as shown in Fig. 5. Theoretical work is also needed to investigate the transmission of Pi 2 electric fields in the magnetosphere-ionosphere-atmosphere-solid Earth system from the nightside auroral latitude to the dayside equator.

In considerations of the relationship of the onset times of low-latitude Pi $2 \mathrm{~s}$ with the auroral breakups as shown in Fig. 12, the comparison between the onset of energetic particle injections at $L=6.6$ and the start of the auroral breakups (Liou et al., 2001b), and the Alfvén transit time ( $\sim 1 \mathrm{~min}$ ) of Pi 2 waves from the magnetotail around 9 $R_{E}$ into the polar ionosphere, we suggest that the particle energization and the Pi 2 generation must take place almost at the same time in the near magnetotail.

This review of Pi 2 magnetic pulsations observed at the CPMN stations demonstrates the usefulness of multi-station observations. Imaging the Earth's magnetosphere by using ground-based magnetometer arrays is reaffirmed as one of the major techniques for investigating the dynamic features of solar wind-magnetosphere interactions. Magnetic field 1 -sec data from coordinated ground-based network stations make it possible to (1) study magnetospheric processes by distinguishing temporal changes and spatial variations in the phenomena, (2) clarify the global structures and propagation characteristics of magnetospheric variations in the latitudinal and longitudinal directions, and (3) understand the generation mechanisms of the global solar-terrestrial phenomena. Considering the essential importance of simultaneous satellite-ground observations and the cost-effectiveness of expensive satellites, we propose that any in situ measurements by the ISTP (GEOTAIL, WIND, POLAR, SOHO, CLUSTER, and INTERBALL) satellites should be coordinated with ground-based network observations for detecting fundamental geophysical phenomena such as magnetic 
storms, magnetospheric substorms, and global-mode ULF waves.

Acknowledgments. Our sincere thanks go to all members of the CPMN project for their ceaseless support. The authors would like to express their thanks to Dr. C.-I. Meng for his kind permission of collaborative analysis between the Polar image data and the CPMN data. The CPMN project is financially supported by the Ministry of Education, Science and Culture of Japan (and Japan Society for the Promotion of Science) as the Grant-in Aid for Overseas Scientific Survey $(05041060,0841105,10041122,12373003)$. The editor thanks P. Sutcliffe and Y. Tonegawa for their assistance in evaluating this paper

\section{References}

Chen, L. and A. Hasegawa, A theory of long-period magnetic pulsations, 1, Steady state excitation of field line resonances, J. Geophys. Res., 79, 1024-1032, 1974a.

Chen, L. and A. Hasegawa, A theory of long-period magnetic pulsations, 2, Impulse excitation of surface eigenmode, J. Geophys. Res., 79, 1033$1037,1974 b$

Cheng, C.-C., J.-K. Chao, and K. Yumoto, Spectral power of low-latitude Pi 2 pulsations at the $210^{\circ}$ magnetic meridian stations and plasmaspheric cavity resonances, Earth Planets Space, 52, 615-627, 2000.

Lester, M., H. J. Singer, D. P. Smits, and W. J. Hughes, Pi 2 pulsations and the substorm current wedge: Low-latitude polarization, J. Geophys. Res., 94, 17133-17141, 1989.

Li, Y., K. Yumoto, M. Itonaga, M. Shinohara, T.-I. Kitamura, and the $210^{\circ}$ MM group, Equatorial Pi 2's as indicators of substorms and the relation between dayside and nightside Pi 2's, in SUBSTORMS-4, Edited by S. Kokubun and Y. Kamide, pp. 555-558, Terra Scientific Publ. Comp/Kluwer Academic Publ., 1998a.

Li, Y., K. Yumoto, K. Liou, S. Otani, and C.-I. Meng, Pi 2 pulsations as indicators of the substorms, Abstract of the Fall Meeting of AGU, San Francisco, on Dec. 6-10, 1998, 1998b.

Li, Y., K. Yumoto, and the $210^{\circ} \mathrm{MM}$ Magnetic Observation Group, Local time dependence of Pi 2 pulsations observed along the $210^{\circ}$ magnetic meridian, Mem. Fac. Sci., Kyushu Univ., 31(1), 11-18, 2000.

Lin, C. A., L. C. Lee, and Y. J. Sun, Observations of Pi 2 pulsations at a very low latitude $(L=1.06)$ station and magnetospheric cavity resonances, J. Geophys. Res., 96, 21105-21114, 1991.

Liou, K., C.-I. Meng, A. T. Lui, P. T. Newell, M. Brittnacher, G. Parks, and M. Nose, A fresh look at substorm onset identifiers, in SUBSTORMS-4, edited by S. Kokubun and Y. Kamide, pp. 247-252, Terra Scientific Publ. Comp/Kluwer Academic Publ., 1998

Liou, K., C.-I. Meng, P. T. Newell, K. Takahashi, S.-I. Ohtani, and A. T. Lui, Evaluation of low-latitude Pi 2 pulsations as indicator of substorm onset using Polar ultraviolet imagery, J. Geophys. Res., 105, 2495-2505, 2000

Liou, K., P. T. Newell, D. G. Sibeck, C.-I. Meng, M. Brittnacher, and G. Parks, Observation of IMF and seasonal effects in the location of auroral substorm onset, J. Geophys. Res., 106, 5799-5810, 2001a

Liou, K., C.-I. Meng, P. T. Newell, A. T. Lui, G. D. Reeves, and R. D. Belian, Particles injections with auroral expansions, J. Geophys. Res., 106, 5873-5881, 2001b.

McPherron, R. L., C. T. Russel, and M. P. Aubry, Satellite studies of magnetospheric substorms on August 15, 1968, Phenomenological model for substorm, J. Geophys. Res., 78, 3131-3149, 1973

Ohtani, S., F. Creutzberg, T. Mukai, H. Singer, A. T. Y. Lui, M. Nakamura, P. Prikryl, K. Yumoto, and G. Rostoker, Substorm onset timing: The December 31, 1995 event, J. Geophys. Res., 104, 17499-17520, 1999.

Olson, J.V., Pi 2 pulsations and substorm onsets: A review, J. Geophys. Res., 104, 17499-17520, 1999.

Osaki, H., K. Yumoto, K. Fukao, K. Shiokawa, F. W. Menk, B. J. Fraser, and the $210^{\circ} \mathrm{MM}$ Magnetic Observation Group, Characteristics of lowlatitude Pi 2 pulsations along the $210^{\circ}$ magnetic meridian, J. Geomag. Geoelectr., 48, 1421-1430, 1996.

Osaki, H., K. Takahashi, H. Fukunishi, T. Nagatsuma, H. Oya, A Matsuoka, and D. K. Milling, Pi 2 pulsations observed from the Akebono satellite in the plasmasphere, J. Geophys. Res., 103, 17605-17615, 1998.

Saito, T., Geomagnetic pulsations, Space Sci. Rev., 10, 319-412, 1969.

Saito, T., K. Yumoto, and K. Koyama, Magnetic pulsation Pi 2 as a sensitive indicator of magnetic substorm, Planet. Space Sci., 24, 1025-1029,
1976

Sakurai, T. and T. Saito, Magnetic pulsation Pi 2 and substorm onset, Planet Space Sci., 24, 573-577, 1976.

Samson, J. C. and G. Rostoker, Latitude-dependent characteristics of high latitude Pc 4 and Pc 5 micropulsations, J. Geophys. Res., 77, 6133-6144, 1972.

Shinohara, K., K. Yumoto, A. Yoshikawa, O. Saka, S. I. Solovyev, E. F. Vershinin, N. B. Trivedi, J. M. Da Costa, and the $210^{\circ}$ MM Magnetic Observation Group, Wave characteristics of daytime and nighttime Pi 2 pulsations at the equatorial and low latitudes, Geophys. Res. Lett., 24(18), 2279-2282, 1997.

Solovyev, S. I., D. G. Baishev, E. S. Barkova, N. E. Molochushkin, and $\mathrm{K}$. Yumoto, Pi 2 magnetic pulsations of auroral arc current system, Geophys. Res. Lett., 27(13), 1839-1842, 2000.

Southwood, D. J., Some features of field line resonance in the magnetosphere, Planet. Space Sci., 22, 483-491, 1974.

Stuart, W. F., A mechanism of selective enhancement of Pi $2 \mathrm{~s}$ by the plasmapause, J. Atmos. Terr. Phys., 36, 851-859, 1974.

Sutcliffe, P. R. and K. Yumoto, On the cavity mode nature of low-latitude Pi 2 pulsations, J. Geophys. Res., 96, 1543-1551, 1991.

Tachihara, H., M. Shinohara, M. Shimoizumi, O. Saka, and T.-I. Kitamura, Magnetometer system for studies of the equatorial electrojet and micropulsations, J. Geomag. Geoelectr., 48, 1311-1319, 1996.

Takahashi, K., S. Ohtani, and K. Yumoto, AMPTE CCE observations of Pi 2 pulsations in the inner magnetosphere, Geophys. Res. Lett., 19, 1447-1450, 1992

Takahashi, K., S. I. Ohtani, and B. J. Anderson, Statistical analysis of Pi 2 pulsations observed by the AMPTE CCE spacecraft in the inner magnetosphere, J. Geophys. Res., 100, 21929-21941, 1995.

Takahashi, K., B. J. Anderson, and K. Yumoto, Upper Atmospheric Research Sattelite observation of a Pi 2 pulsation, J. Geophys. Res., 104 25035-25045, 1999.

Uozumi, T., Study on generation and propagation mechanisms of Pi 2 magnetic pulsations; Toward the identification of the substorm onset region, Thesis for the Degree of Doctor of Science in Kyushu University, Sept. 25, 2000.

Uozumi, T., K. Yumoto, H. Kawano, A. Yoshikawa, J. V. Olson, S. I. Solovyev, and E. F. Vershinin, Characteristics of energy transfer of Pi 2 magnetic pulsations: Latitudinal dependence, Geophys. Res. Lett., 27(11), 1619-1623, 2000

Yeoman, T. K. and D. Orr, Phase and spectral power of mid-latitude Pi 2 pulsations: evidence for a plasmasphere cavity resonances, Planet. Space Sci., 37, 1367-1383, 1989 .

Yeoman, T. K., M. P. Freeman, G. D. Reeves, M. Lester, and D. Orr, A comparison of mid-latitude $\mathrm{Pi} 2$ pulsations and geostationary orbit particle injections as substorm indicators, J. Geophys. Res., 99, 40854093, 1994

Yumoto, K., Generation and propagation mechanisms of low-latitude magnetic pulsations-A review, J. Geosphys., 60, 79-105, 1986.

Yumoto, K., External and internal sources of low-frequency MHD waves in the magnetosphere-A review, J. Geomag. Geoelectr., 40, 293-311, 1988.

Yumoto, K., Evidence of magnetic cavity Pi 2 waves, J. Geomag. Geoelectr., 42, 1281-1290, 1990.

Yumoto, K. and The $210^{\circ} \mathrm{MM}$ Magnetic Observation Group, Initial results from the $210^{\circ}$ magnetic meridian project-Review, J. Geomag. Geoelectr., 47, 1197-1213, 1995.

Yumoto, K. and the $210^{\circ} \mathrm{MM}$ Magnetic Observation Group, The STEP $210^{\circ}$ magnetic meridian network project, J. Geomag. Geoelectr., 48, 1297-1309, 1996.

Yumoto, K., K. Takahashi, T. Saito, F. W. Menk, B. J. Fraser, T. A. Potemra and L. J. Zanetti, Some aspects of the relation between Pi 1-2 magnetic pulsations observed at $L=1.3-2.1$ on the ground and substormassociated magnetic field variations in the near-earth magnetotail observed by AMPTE/CCE, J. Geophys. Res., 94, 3611-3618, 1989.

Yumoto, K, H. Osaki, K. Fukao, K. Shiokawa, Y. Tanaka, S. I. Soloveyev, G. Krymskij, E. F. Vershinin, V. F. Osinin, and $210^{\circ}$ MM Magnetic Observation Group, Correlation of high- and low-latitude Pi 2 magnetic pulsations observed at $210^{\circ}$ magnetic meridian chain stations, J. Geomag. Geoelectr., 46, 925-935, 1994.

K. Yumoto (e-mail: yumoto@geo.kyushu-u.ac.jp) and the CPMN Group 